\title{
Pubertal Changes in Calcium Kinetics in Girls Assessed Using ${ }^{42} \mathrm{Ca}$
}

\author{
STEVEN A. ABRAMS \\ Department of Pediatrics, USDA/ARS Children's Nutrition Research Center, Baylor College of Medicine and \\ Texas Children's Hospital, Houston. Texas 77030
}

\begin{abstract}
The rate of calcium deposition in bone $\left(V_{0}^{+}\right)$ and the size of the exchangeable calcium pool in bone (EP) were measured in 50 girls aged 4.9 to $16.7 \mathrm{y}$ using i.v. administered ${ }^{42} \mathrm{Ca}$. Both $V_{0}^{+}$and EP reached a maximum during early puberty and decreased in late puberty and more than 2 y postmenarche. In contrast, the initial mass of calcium distribution did not decrease in late puberty. The ratio of calcium deposition in bone to the exchangeable pool size, i.e. $k_{0}^{+}=V_{0}^{+} / E P$, was more closely correlated with length of time since menarche $(r=0.83, p<0.001)$ than with age $(r=0.65, p<0.001)$, weight $(r=0.51, p<$ $0.001)$, or body mass index $(r=0.28, p=0.05)$. The lower $k_{0}{ }^{+}$in late puberty indicates that as bone matures the fraction of the calcium pool that enters bone decreases. (Pediatr Res 34: 455-459, 1993)
\end{abstract}

Abbreviations
$V_{\circ}^{+}$, rate of calcium deposition in bone
EP, exchangeable calcium pool in bone
MPCa, initial mass of calcium distribution
$\boldsymbol{k}_{\mathrm{o}}^{+}$, rate constant for calcium deposition
FSD, fractional standard deviation
BMC, bone mineral content
BMD, bone mineral density

Puberty is recognized as a period of maximal growth, with the peak rate of bone mass accumulation and calcium retention occurring during this period (1-3). Current recommendations for calcium intake in children suggest an increased intake beginning at $11 \mathrm{y}$ of age, which is after the onset of puberty in many girls $(1,4)$.

Although previous studies have demonstrated the importance of pubertal development on bone mineralization, they have not specifically described the changes in calcium metabolism that accompany this development. The use of stable isotopes permits the evaluation of the kinetic parameters of calcium metabolism in children, including the $V_{o}^{+}$and the mass of the EP. The ratio of the these parameters, ${k_{0}}^{+}$, provides a measure of the fraction of the calcium that enters the skeleton per unit time (5).

A previous study reported that each of these parameters of calcium metabolism was higher in children than in adults (5).

Received February 22, 1993; accepted June 3, 1993.

1 This work is a publication of the U.S. Department of Agriculture (USDA)/ Agricultural Research Service (ARS) Children's Nutrition Research Center, Department of Pediatrics, Baylor College of Medicine and Texas Children's Hospital, Houston, TX. This project has been funded in part with federal funds from the USDA/ARS under Cooperative Agreement number 58-6250-1-003. The contents of this publication do not necessarily reflect the views or policies of the USDA. nor does mention of trade names, commercial products, or organizations imply endorsement by the U.S. Government.

Correspondence: Steven A. Abrams, M.D. Children's Nutrition Research Center. 1100 Bates St., Houston, TX 77030.
The present study was designed to evaluate the developmental course of these kinetic parameters in girls and relate them to pubertal and anthropometric changes.

\section{MATERIALS AND METHODS}

Study design. Fifty healthy girls aged 4.9-16.7 y were enrolled and completed this study. Thirty-nine subjects were Caucasian, six were African-American, two Asian, two Hispanic, and one had one Caucasian and one African-American parent. Results for the kinetic parameters EP and $V_{\mathrm{o}}^{+}$for seven of the 50 subjects have been previously reported (6).

Written informed consent was obtained from the parents for each study, with written assent obtained from children aged 7 and older. The Institutional Review Board of Baylor College of Medicine approved this protocol. Stable isotope studies were performed as described previously (5-7). Each study was begun approximately $\mathrm{l} \mathrm{h}$ after the subject received her usual breakfast. For this study, $0.08 \mathrm{mg} / \mathrm{kg}{ }^{42} \mathrm{Ca}$ was given i.v. to each subject over $5 \mathrm{~min}$; serum samples were drawn via a "heparin loc" catheter at $6,12,20,30,45,60,120,180,240$, and $480 \mathrm{~min}$ after the end of the tracer infusion. Subjects were asked to void before the infusion and to complete a 24-h urine collection (in 8-h aliquots) while at the Metabolic Research Unit of the USDA/ ARS Children's Nutrition Research Center in Houston, TX. After completion of the urine collection, subjects were discharged and instructed to collect three spot urine samples daily (first morning, midday, and before bedtime) for 6 additional d. All serum and urine samples were analyzed for isotope ratio by thermal ionization mass spectrometry as described below. Total urinary calcium excretion was measured during the first $24 \mathrm{~h}$.

Three-d dietary records were maintained beginning with the study day for each subject. Subjects were given a diet similar to their usual home diet (as determined by 24-h recall) while at the Children's Nutrition Research Center.

Subjects were asked to identify their Tanner stage (stage 1-5) by circling a picture that most closely matched their own development (8). Small children were assisted by their parents. Tanner stage in this report refers to the self-reported breast staging (9). Post-menarcheal subjects were questioned to identify the month they had reached menarche.

Sample analysis. Urine and serum samples were prepared for mass spectrometric analysis as previously described using an oxalate precipitation technique $(5,6)$. Samples were analyzed for isotopic enrichment with a Finnigan (Bremen, Germany) MAT 261 magnetic sector thermal ionization mass spectrometer. Each sample was analyzed for the ratio of ${ }^{42} \mathrm{Ca} /{ }^{43} \mathrm{Ca}$ with correction for fractionation to the reference ${ }^{44} \mathrm{Ca} /{ }^{43} \mathrm{Ca}$ ratio. Accuracy of this technique for natural abundance samples compared with standard data is $0.05 \%$. Precision, including sequential measurement of the same sample (on different filaments) over a period of time, was $0.1 \%$ or better (6). Enrichments varied from approximately $80 \%$ at $6 \mathrm{~min}$ (serum) to $1-3 \%$ at $7 \mathrm{~d}$ (urine).

Calculations. The general form of the three-term exponential 
equation used to describe the time course of tracer excess, $y$, in serum and urine over the 7-d period after tracer administration was:

$$
y=A_{1} e^{-a_{1} t}+A_{2} e^{-a_{2} t}+A_{3} e^{-a_{3} t}
$$

The SAAM (simulation, analysis, and modeling) program was used to determine the linear least-squares best-fit curve to the data and to calculate the coefficients $A_{i}$ and exponents $a_{i}$ in equation 1 for each subject. As previously described (5), the EP is derived from the intercept of the third term of equation 1 :

$$
E P=\left(1 / A_{3}\right)
$$

The rate at which calcium moved from the EP into the skeleton is indicated by $V_{0}^{+}$and calculated as:

$$
V_{\mathrm{o}}^{+}=\left(\mathrm{a}_{3} \cdot \mathrm{EP}\right)-(\text { urinary }+ \text { endogenous fecal excretion })
$$

The mass of the EP is calculated from equation 2 after correcting for the dose administered and the fractional abundance of the isotope administered. The fractional abundance represents the naturally occurring fraction of $\mathrm{Ca}$ of the administered isotope (i.e. 0.00646 for ${ }^{42} \mathrm{Ca}$ ). The third component of equation 1 $\left(\mathrm{A}_{3} \mathrm{e}^{-\mathrm{a}_{3} t}\right)$ and therefore EP and $V_{0}^{+}$, were principally derived from the urine disappearance curve between 24 and $120 \mathrm{~h}$ after tracer administration. Endogenous excretion in equation 3 was estimated as $1.5 \mathrm{mg} \cdot \mathrm{kg}^{-1} \cdot \mathrm{d}^{-1}$. As previously shown, the effects in children of using an estimation of endogenous excretion on the calculated $V_{\mathrm{o}}^{+}$are negligible (5).

The reliability of the calculated values is represented by the FSD of the coefficients and exponents of equation 1. We have previously described the methods for determining the FSD for the calculated kinetic parameters (equations 2 and 3) (5). Based on 25-30 samples for each subject, the FSD was generally 3-5\% for each kinetic parameter.

The intercept at $t=0$ in equation 1, i.e., $y=\Sigma\left(A_{1}+A_{2}+\right.$ $A_{3}$ ), enatled the direct calculation of the apparent initial mass of distribution of the tracer. This has previously been referred to as the mass of the rapidly turning over pool, MPCa (10).

The rate constant for bone calcium deposition, $k_{0}{ }^{+}$, is calculated as the ratio of $V_{\mathrm{o}}^{+} / \mathrm{EP}$ and is expressed as $\mathrm{d}^{-1}$.

Statistical analysis. Comparison of kinetic parameters among subjects who were prepubertal (Tanner stage 1), early pubertal (Tanner stages 2 and 3), and late pubertal (Tanner stages 4 and 5 ) was done by analysis of variance techniques. After identifying significant differences among the three groups $(p<0.01)$ by analysis of variance, the Fisher's least significant difference test was used to identify significant pair-wise group differences.

The relationship between kinetic parameters and months since menarche was evaluated by linear regression analysis. The relationships among age, weight, body mass index, and time since menarche and kinetic parameters were evaluated by multiple regression analysis. In this analysis, the effect of 1 ) one of the anthropometric variables and 2) time since menarche was evaluated versus the desired kinetic variable. All results listed are presented as the mean \pm SD.

\section{RESULTS}

Characteristics of the study population as grouped by pubertal development are shown in Table 1. Individual results for each subject are contained in Table 2 . Serum $\mathrm{Ca}$, phosphorus, and albumin were within the normal range for all study subjects. All subjects had both height and weight $z$ scores between -2.0 and 2.0 except for one early-pubertal subject whose height $z$ score was 2.1 and weight $z$ score was 3.5 . Mean calcium intake was $933 \pm 263 \mathrm{mg} / \mathrm{d}(\mathrm{SD})$ and was not related to age, pubertal, or menarcheal status.

Results for kinetic parameters based on pubertal development are shown in Table 3 . EP and $V_{0}^{+}$were greatest in early pubertal girls. The $k_{\mathrm{o}}{ }^{+}$was significantly greater in prepubertal and early pubertal girls than in late pubertal girls.

The relationship between months since menarche and kinetic parameters are shown in Figures 1-3. Early postmenarcheal subjects had kinetic parameters similar to those of premenarcheal subjects. All subjects more that 24 mo postmenarche, however. had lower EP and $V_{\mathrm{o}}^{+}$. The number of subjects studied during the first 24 mo after menarche was small $(n=6)$ and limited more detailed analysis of precisely when the decreases occurred and the rates at which they decreased.

Follow-up of all premenarcheal subjects for at least 6 mo identified two girls who reached menarche 6 mo after the study was performed. Results from these two subjects (during their initial premenarcheal study) were similar to those of the early postmenarcheal females; $k_{\mathrm{o}}^{+}$averaged $0.37 \mathrm{~d}^{-1}$. EP averaged 6.62 $\mathrm{g}$, and $V_{\mathrm{o}}^{+}$averaged $2.24 \mathrm{~g} / \mathrm{d}$. These values were virtually identical to the values for early postmenarcheal females and suggested that there were no distinct changes in kinetic parameters associated with the onset of menarche.

When evaluated pair-wise using linear regression analysis, $k_{\mathrm{o}}^{+}$ was more closely correlated with length of time since menarche $(r=0.83, p<0.001)$ than with age $(r=0.65, p<0.001)$, weight $(r=0.51, p<0.001)$, or body mass index, $(r=0.28, p=0.05)$. Multiple regression analysis showed that EP and $V_{0}^{+}$were more closely correlated with the number of months postmenarche than with age, weight, height, or body mass index. The $k_{0}{ }^{+}$was more closely related to months postmenarche $(p=0.0002)$ than age $(p=0.014)$.

MPCa increased in early and late pubertal girls compared with prepubertal girls. (Table 3). Combining data from all groups showed a mean MPCa of $18 \pm 6 \mathrm{mg} / \mathrm{kg}$, which was not different among pubertal groups.

\section{DISCUSSION}

We have demonstrated a decline in the calcium kinetic parameters associated with bone calcium deposition during the late pubertal, postmenarcheal period in adolescent females. We found much lower $V_{\mathrm{o}}^{+}$and $k_{\mathrm{o}}^{+}$for girls in this study who were more than 24 mo postmenarche (Figs. 2 and 3 ) than for prepubertal and early pubertal girls. The lower $k_{0}{ }^{+}$in late puberty demonstrates that as bone matures there is a decrease in the fraction of the exchangeable pool that enters bone.

Our data showing decreased calcium kinetic parameters during late puberty are in agreement with bone density studies that demonstrate the relatively greater importance of early adolescence compared with late adolescence in accumulating bone mass $(2,3,11-15)$. Gordon et al. (13) demonstrated that little increase occurs in lumbar spine BMC or BMD after age 14. On the basis of lumbar spine densitometric data, the authors concluded that "in females, the puberty-associated contributions to peak bone mass are $39 \%$ for BMD and $55 \%$ for BMC." Bonjour et al. (14) also looked at bone mineralization after menarche and

\begin{tabular}{|c|c|c|c|c|c|c|}
\hline & $n$ & Age (y) & $\begin{array}{c}\text { Weight } \\
(\mathrm{kg})\end{array}$ & $\begin{array}{c}\text { Body mass index } \\
\left(\mathrm{kg} / \mathrm{m}^{2}\right)\end{array}$ & $\begin{array}{l}\text { Height }= \\
\text { score }\end{array}$ & $\begin{array}{l}\text { Weight z } \\
\text { score }\end{array}$ \\
\hline Prepubertal (Tanner 1) & 23 & $8.1 \pm 1.8^{*}$ & $25.9 \pm 6.2$ & $15.9 \pm 2.1$ & $0.09 \pm 0.97$ & $-0.08 \pm 0.98$ \\
\hline Early pubertal (Tanner 2.3) & 17 & $12.6 \pm 2.5$ & $42.6 \pm 8.1$ & $17.8 \pm 2.4$ & $0.74 \pm 0.92$ & $0.02 \pm 1.20$ \\
\hline Late pubertal (Tanner 4,5 ) & 10 & $15.4 \pm 0.9$ & $59.3 \pm 8.7$ & $22.2 \pm 3.4$ & $0.05 \pm 0.70$ & $0.27 \pm 0.90$ \\
\hline
\end{tabular}
found a "substantial augmentation" in BMC and BMD during

Table 1. Anthropometric characteristics of study subjects

* Mean \pm SD 
Table 2. Anthropometric and calcium kinetics values of study subjects

\begin{tabular}{|c|c|c|c|c|c|c|}
\hline $\begin{array}{c}\text { Subject } \\
\text { no. }\end{array}$ & Age $(y)$ & $\begin{array}{l}\text { Weight } \\
(\mathrm{kg})\end{array}$ & $\begin{array}{l}\text { Height } \\
(\mathrm{cm})\end{array}$ & $\begin{array}{c}\text { Tanner stage } \\
\text { (breast) }\end{array}$ & $\begin{array}{c}\text { Total EP } \\
(\mathrm{g})\end{array}$ & $V_{\mathrm{o}}^{+}(\mathrm{g} / \mathrm{d})$ \\
\hline 1 & 4.9 & 15.6 & 108.4 & 1 & 3.14 & 1.06 \\
\hline 2 & 5.2 & 19.3 & 117.4 & 1 & 4.23 & 1.29 \\
\hline 3 & 5.5 & 21.0 & 112.3 & 1 & 2.75 & 1.39 \\
\hline 4 & 5.9 & 15.3 & 106.8 & 1 & 2.67 & 1.08 \\
\hline 5 & 5.9 & 21.3 & 114.7 & 1 & 2.94 & 1.32 \\
\hline 6 & 6.1 & 20.0 & 114.0 & 1 & 4.20 & 1.58 \\
\hline 7 & 7.8 & 21.6 & 129.5 & 1 & 3.74 & 1.60 \\
\hline 8 & 7.9 & 33.8 & 132.2 & 1 & 4.77 & 2.59 \\
\hline 9 & 8.0 & 29.3 & 134.7 & 1 & 4.70 & 1.90 \\
\hline 10 & 8.0 & 28.9 & 134.7 & 1 & 4.13 & 1.61 \\
\hline 11 & 8.1 & 22.5 & 121.3 & 1 & 5.48 & 1.35 \\
\hline 12 & 8.3 & 32.7 & 132.3 & 1 & 4.06 & 1.85 \\
\hline 13 & 8.7 & 22.9 & 133.9 & 1 & 4.91 & 1.63 \\
\hline 14 & 8.7 & 49.6 & 143.8 & 2 & 5.28 & 2.43 \\
\hline 15 & 8.9 & 34.0 & 139.6 & 1 & 7.26 & 2.84 \\
\hline 16 & 8.9 & 25.9 & 120.5 & 1 & 4.20 & 1.51 \\
\hline 17 & 8.9 & 25.9 & 130.9 & 1 & 6.58 & 1.96 \\
\hline 18 & 9.0 & 22.9 & 125.8 & 1 & 4.55 & 1.79 \\
\hline 19 & 9.6 & 30.5 & 131.7 & 1 & 4.41 & 1.72 \\
\hline 20 & 9.7 & 37.3 & 139.1 & 2 & 7.85 & 3.29 \\
\hline 21 & 9.8 & 28.9 & 134.9 & 1 & 5.60 & 1.73 \\
\hline 22 & 9.8 & 38.4 & 137.0 & 1 & 4.39 & 1.85 \\
\hline 23 & 9.9 & 37.7 & 143.3 & 2 & 5.45 & 2.89 \\
\hline 24 & 10.3 & 33.2 & 139.6 & 1 & 3.59 & 2.01 \\
\hline 25 & 10.3 & 38.8 & 143.5 & 2 & 5.00 & 1.81 \\
\hline 26 & 10.9 & 26.2 & 135.5 & 1 & 4.90 & 1.96 \\
\hline 27 & 10.9 & 35.7 & 152.9 & 2 & 6.61 & 2.69 \\
\hline 28 & 11.1 & 33.3 & 136.9 & 3 & 5.19 & 2.35 \\
\hline 29 & 11.2 & 28.9 & 145.4 & 2 & 4.98 & 1.97 \\
\hline 30 & 11.4 & 40.6 & 151.0 & 2 & 7.99 & 3.36 \\
\hline 31 & 11.4 & 32.1 & 141.5 & 1 & 4.99 & 1.89 \\
\hline 32 & 11.7 & 33.4 & 140.5 & 2 & 5.26 & 1.57 \\
\hline 33 & 12.0 & 41.8 & 157.1 & 3 & 6.01 & 2.38 \\
\hline 34 & 13.0 & 55.7 & 165.2 & 2 & 10.18 & 3.46 \\
\hline 35 & 14.0 & 71.1 & 169.1 & 5 & 5.55 & 1.61 \\
\hline 36 & 14.3 & 50.9 & 161.4 & 5 & 4.54 & 1.25 \\
\hline 37 & 14.4 & 53.8 & 167.7 & 3 & 6.68 & 2.15 \\
\hline 38 & 14.5 & 43.5 & 174.4 & 3 & 8.06 & 2.24 \\
\hline 39 & 14.8 & 54.3 & 168.7 & 3 & 7.73 & 2.40 \\
\hline 40 & 14.9 & 45.7 & 158.9 & 5 & 4.72 & 0.95 \\
\hline 41 & 15.1 & 68.7 & 154.0 & 5 & 5.43 & 1.06 \\
\hline 42 & 15.4 & 58.3 & 164.0 & 4 & 5.41 & 1.39 \\
\hline 43 & 15.8 & 48.6 & 167.3 & 3 & 4.93 & 1.60 \\
\hline 44 & 15.9 & 43.6 & 167.5 & 3 & 6.57 & 1.82 \\
\hline 45 & 16.0 & 57.7 & 157.9 & 5 & 5.12 & 1.35 \\
\hline 46 & 16.1 & 54.5 & 161.8 & 5 & 3.87 & 0.86 \\
\hline 47 & 16.2 & 57.8 & 161.0 & 5 & 4.57 & 1.14 \\
\hline 48 & 16.4 & 49.2 & 165.5 & 5 & 5.05 & 0.88 \\
\hline 49 & 16.7 & 50.5 & 167.1 & 3 & 5.20 & 1.27 \\
\hline 50 & 16.7 & 69.1 & 168.3 & 5 & 6.43 & 1.53 \\
\hline
\end{tabular}

Table 3. Calcium kinetic parameters in study subjects

\begin{tabular}{lcccc}
\hline & EP* $(\mathrm{g})$ & $V_{0}^{+} \dagger(\mathrm{g} / \mathrm{d})$ & $k_{\mathrm{o}}^{+} \ddagger\left(\mathrm{d}^{-1}\right)$ & $\mathrm{MPCa}(\mathrm{g})$ \\
\hline Prepubertal (Tanner 1) & $4.44 \pm 1.12 \|$ & $1.72 \pm 0.42$ & $0.39 \pm 0.08$ & $0.51 \pm 0.22$ \\
Early pubertal (Tanner 2, 3) & $6.41 \pm 1.50$ & $2.33 \pm 0.64$ & $0.37 \pm 0.08$ & $0.81 \pm 0.41$ \\
Late pubertal (Tanner 4, 5) & $5.08 \pm 0.70$ & $1.20 \pm 0.27$ & $0.24 \pm 0.04$ & $0.88 \pm 0.29$ \\
\hline
\end{tabular}

* Early pubertal different from prepubertal and late pubertal, $p<0.01$.

+ Each group different, $p<0.01$.

$\ddagger$ Late pubertal different from prepubertal and early pubertal, $p<0.01$.

$\S$ Prepubertal different from early and late pubertal, $p<0.01$.

$\|$ Mean $\pm \mathrm{SD}$. 


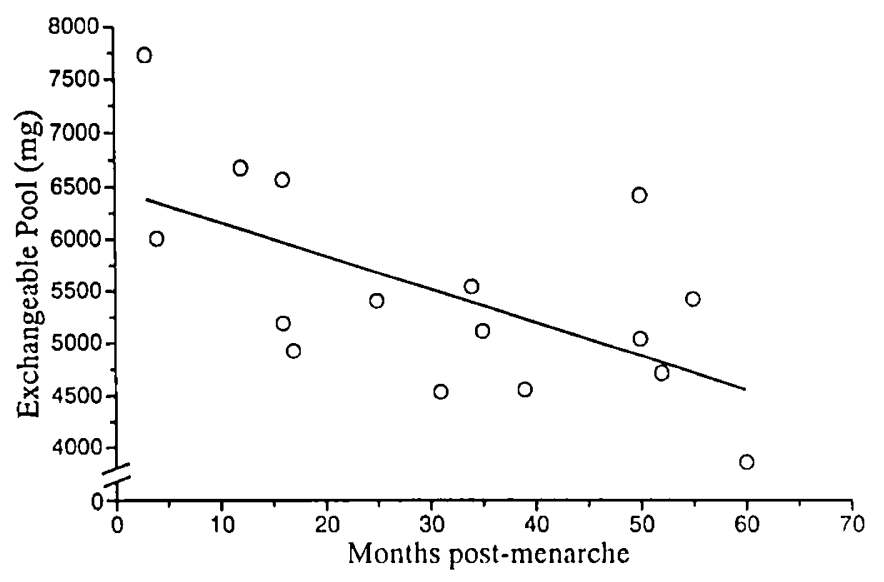

Fig. 1. The linear relationship between EP and mean months postmenarche: $y=-32 x+6484, r=0.61, p<0.01$. Mean value for healthy adults (aged 23-39) was $5.3 \mathrm{~g}(5)$.

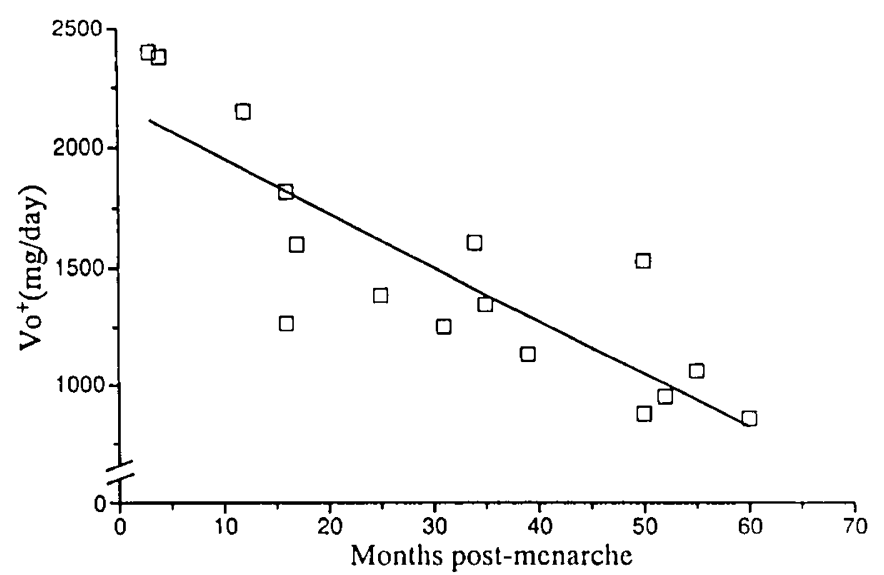

Fig. 2. The linear relationship between $V_{\mathrm{o}}{ }^{+}$and months postmenarche: $y=-23 x+2184 . r=0.85, p<0.0001$. Mean value for healthy adults (aged 23-39) was $0.7 \mathrm{~g} / \mathrm{d}(5)$.

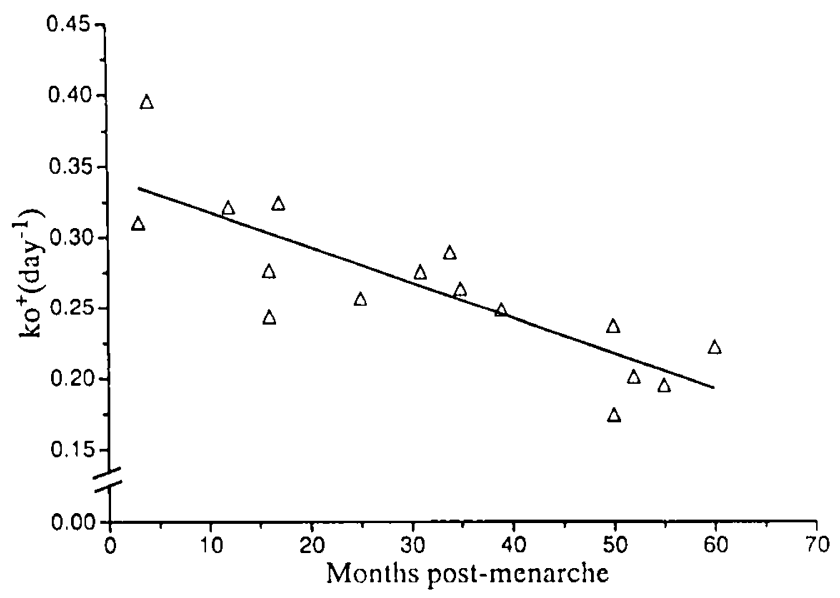

Fig. 3. The linear relationship between $k_{0}{ }^{+}$and months postmenarche: $y=-0.002 x+0.343, r=0.83, p<0.0001$. Mean value for healthy adults (aged 23-39) was $0.12 \mathrm{~d}^{-1}(5)$.

the $2 \mathrm{y}$ after menarche, a "minor increase" in the next $2 \mathrm{y}$, and no increase in the 4th to 8th y after menarche. Johnston et al. (15) showed that calcium supplementation in twins led to a significant increase in BMD in prepubertal but not pubertal twins.

We previously reported a mean $V_{\mathrm{o}}^{+}$of $0.7 \pm 0.2 \mathrm{~g} / \mathrm{d}$ and a mean $k_{\mathrm{o}}{ }^{+}$of $0.12 \pm 0.03 \mathrm{~d}^{-1}$ in young (age 23-39) adults. The values in this study for late pubertal girls of $1.20 \pm 0.27 \mathrm{~g} / \mathrm{d}$ for $V_{0}^{+}$and $0.24 \pm 0.04 \mathrm{~d}^{-1}$ for $k_{\circ}{ }^{+}$demonstrate that, although bone calcium deposition activity is lower in late puberty than in early puberty, it remains greater than in adulthood. These results are consistent with reports by Matkovic (16) and Recker et al. (17) demonstrating an increase in bone mass during the third decade of life.

The degree to which bone mineralization can be affected by large calcium intakes remains uncertain. Previous studies, however, have suggested that calcium intake does not have a major effect on $V_{0}^{+}$and it is unlikely that increasing calcium intake after puberty would significantly increase $V_{0}^{+}(18)$. Nevertheless, the long-term effects of increasing calcium intake on $V_{\mathrm{o}}{ }^{+}$and $\mathrm{k}_{\mathrm{o}}{ }^{+}$ at any age are unknown.

One important distinction between measurements of BMC or BMD and those of calcium kinetics is that the kinetic measurements may enable the rapid assessment of changes that occur with disease or therapeutic intervention. It is probable that changes in calcium kinetic parameters precede measurable changes in bone density, but this has not been demonstrated.

We found that developmental changes in the time zero distribution of tracer (MPCa) were unlike those of the EP in that the size of the MPCa increased in late puberty. On a body weight basis, this pool size was comparable among girls of different pubertal status and adults (previously reported) (19). Using i.v. Ca loading, Bronner et al. (20-22) have shown that approximately $80 \%$ of the initial distribution of $\mathrm{Ca}$ is external to plasma.

Consistent with most previous reports, we have used a sum of exponentials approach to calculate the $\mathrm{Ca}$ kinetic parameters. The coefficients and exponents used in these calculations lead to pool sizes and $V_{o}^{+}$that are mathematically determined entities. i.e. no direct anatomical or physiologic correlates can be made. The method we have used to determine the EP, in which the third term of the sum of exponentials is used, may be viewed as representing the approximate distribution volume of tracer at 24 $\mathrm{h}$ after tracer injection. Unquestionably, there are inhomogeneities in the EP as described by this method. Bronner, however, showed that results from this approach are similar to those obtained by other multicompartmental analysis techniques (23, 24).

Previous studies have used autoradiographic labeling to demonstrate the time-dependent distribution of calcium in bone, and the results demonstrate that during the first 24-h a majority of injected calcium is distributed in newly formed, principally trabecular bone $(5,25) . V_{o}^{+}$may therefore represent $\mathrm{Ca}$ transfer into this superficial bone with subsequent exchange into deeper bone pools. These issues have been extensively reviewed previously $(5,17,20,26)$.

Although some authors have suggested that longer kinetic studies are necessary to define more slowly turning over pools $(22,27)$, numerous studies have demonstrated that $7-d$ studies enable the calculation of useful kinetic parameters by which to assess both developmental changes and maladaptations. For example, differences associated with abnormalities of mineral metabolism and with menopausal changes have been identified with this approach (28). Similarly, pregnancy leads to changes in EP and $V_{0}^{+}$consistent with fetal mineral accretion (29). Human and animal studies have demonstrated that these parameters are altered in situations such as hypo- and hyperparathyroidism (5, $18,24)$

There are few previous reports of calcium kinetic parameters in children; $k_{\mathrm{o}}{ }^{+}$varied from 0.32 to $0.66 \mathrm{~d}-1$ in the seven children aged 3-14 y previously reported (5), Bronner and Lemaire (21) showed, in 1969, that $k_{\mathrm{o}}{ }^{+}$averaged $0.32 \pm 0.05 \mathrm{~d}-1$ in five boys aged 12-13 y, which is comparable to the values for pubertal females in the present study. This similarity suggests that an increased $k_{0}{ }^{+}$is characteristic of childhood and early puberty in both males and females. Bronner and Lemaire demonstrated that $k_{\mathrm{o}}{ }^{+}$is much higher in rats than in humans. They suggest that this difference is related to the larger dietary contribution of 
calcium to the EP size in rats and the higher $V_{0}^{+}$in rats than humans. It would be of interest to evaluate these possibilities by studying the effect of hormonal abnormalities or calcium malabsorption in children on $k_{\mathrm{o}}{ }^{+}$. How kinetic parameters relate to other measures of bone formation and metabolism in children, such as biochemical markers, remains to be determined. Periods of rapid bone formation or of remodeling might be expected to increase $V_{0}^{+}$.

The normal onset of puberty frequently occurs in girls between 8 and 11 y of age. The mean age of menarche for American females is now 12.5 y of age $(2,3)$. Our results suggest that the greatest period of calcium transfer to bone is in the prepubertal and early pubertal periods. We speculate that current recommendations for calcium nutrition, which focus on increasing intake in 11- to 24-y-olds, may need to be adjusted to account for the importance of the early pubertal period.

Acknowledgments. The author thanks the nursing staff of the MRU of the CNRC for nursing care of the study subjects; Jun Zhu, Lily Liang, and Suman Vaidya for technical assistance; Felix Bronner, PhD, Al Yergey, PhD, and Nancy Vieira, MS, for assistance and advice with this project: E. O. Smith, $\mathrm{PhD}$, for biostatistical support; and E. R. Klein for editorial assistance.

\section{REFERENCES}

1. Tanner JM 1990 Foetus into Man: Physical Growth from Conception to Maturity. Harvard University Press, Cambridge. MA, pp 58-73

2. Matkovic V. Fontana D. Tominac C. Goel P. Chesnut CH 1990 Factors that influence peak bone mass formation: a study of calcium balance and the inheritance of bone mass in adolescent females. Am J Clin Nutr 52:878-888

3. Katzman DK, Bachrach LK, Carter DR. Marcus R 1991 Clinical and anthropometric correlates of bone mineral acquisition in healthy adolescent girls. J Clin Endocrinol Metab 73:1332-1339

4. Committee on Dietary Allowances, Food and Nutrition and Board, National Research Council 1989 Recommended Dietary Allowances, 10th Ed. National Academy Press. Washington, DC

5. Abrams SA. Esteban NV, Vieira NE, Sidbury JB, Specker BL, Yergey AL 1992 Developmental changes in calcium kinetics in children assessed using stable isotopes. J Bone Min Res 7:287-293

6. Abrams SA, Silber TJ, Esteban NV, Vieira NE, Stuff JE, Meyers R. Majd M. Yergey AL 1993 Mineral balance and bone turnover in adolescents with anorexia nervosa. J Pediatr 123:326-331

7. Abrams SA, Lipnick RN. Vieira NE, Stuff J. Yergey AL 1993 Calcium absorption in children with juvenile rheumatoid arthritis assessed using stable isotopes. J Rheumatol 20:1196-1200
8. Tanner JM 1962 Growth at Adolescence. 2nd Ed. Blackwell. Oxford, UK

9. Duke PM. Litt IF, Gross RT 1980 Adolescents' self-assessment of sexual maturation. Pediatrics 66:918-920

10. Yergey AL, Abrams SA, Vieira NE. Hillman AL. Covell DG 1990 Recent studies of human calcium metabolism using stable isotopic tracers. Can J Physiol Pharmacol 68:973-976

11. Thomas KA. Cook SD. Bennett JT, Whitecloud TS, Rice JC 1991 Femoral neck and lumbar spine bone mineral densities in a normal population 3-20 years of age. J Pediatr Orthop 11:48-58

12. Guesens P, Cantatore F, Nijs J, Proesmans W, Emma F. Dequeker J 1991 Heterogeneity of growth of bone in children at the spine, radius and total skeleton. Growth Dev Aging 55:249-256

13. Gordon CL, Halton JM. Atkinson SA, Webber CE 1991 The contribution of growth and puberty to peak bone mass. Growth Dev Aging 55:257-262

14. Bonjour J-P. Theintz G. Buchs B. Slosman D. Rizzoli R 1991 Critical years and stages of puberty for spinal and femoral bone mass accumulation during adolescence. J Clin Endocrinol Metab 73:555-563

15. Johnston CC, Miller JZ, Slemenda CW, Reister TK, Hui S, Christian JC, Peacock M 1992 Calcium supplementation and increases in bone mineral density in children. N Engl J Med 327:82-87

16. Matkovic V 1992 Calcium and peak bone mass. J Intern Med 231:151-60

17. Recker RR, Davies M. Hinders SM. Heaney RP. Stegman MR, Kimmel DB 1992 Bone gain in young adult women. JAMA 268:2403-2408

18. Bronner F 1982 Calcium homeostasis. In: Bronner F, Coburn JW (eds) Disorders of Mineral Metabolism. Academic Press. New York. pp 43-102

19. Abrams SA, Esteban NV, Vieira NE. Goans RE, Covell DG. Marini JC. Sidbury JB. Specker BL. Yergey AL 1991 Non-compartmental analysis of calcium kinetics demonstrate developmental changes in mean residence time and abnormalities in body pools in osteopgenesis imperfecta. FASEB J 5:A560(abstr)

20. Bronner F. Bosco JJ. Stein WD 1989 Acute calcium regulation in rats: effect of vitamin D deficiency. Bone Miner 6:141-153

21. Bronner F, Lemaire R 1969 Comparison of calcium kinetics in man and the rat. Calcif Tissue Res 3:238-248

22. Bronner F 1992 Bone and calcium homeostasis. Neurotoxicology 13:775-782

23. Heaney RP 1963 Evaluation and interpretation of calcium-kinetic data in man. Clin Orthop 31:153-183

24. Bronner F 1964 Dynamics and function of calcium. In: Comar CL, Bronner F (eds) Mineral Metabolism: An Advanced Treatise. Vol II. The Elements. Part A. Academic Press, New York, pp 341-444

25. Pond WG. Lovelace FE, Walker EF, Krook L 1969 Distribution of parenterally administered ${ }^{45} \mathrm{Ca}$ in bones of growing pigs. J Anim Sci 29:298-302

26. Aubert JP, Bronner F, Richelle LJ 1963 Quantitation of calcium metabolism. Theory J Clin Invest 42:885-897

27. Jung A. Bartholdi P. Mermillod B. Reeve J. Neer R 1978 Critical analysis of methods for analyzing human calcium kinetics. J Theor Biol 73:131-157

28. Heaney RP. Heaney RP, Recker RR, Saville PD 1978 Menopausal changes in bone remodeling. J Lab Clin Med 92:964-970

29. Heaney R, Skillman TG 1971 Calcium metabolism in normal human pregnancy. J Clin Endocrinol 33:661-670

30. Howard CP 1983 Endocrinology of puberty. In: Hoffman A, Greydanus D. (eds) Adolescent Medicine. 2nd Ed. Appleton and Lange. East Norwalk. CT 